\title{
Farklı kültürlerde jinekolojik ve meme kanserli kadın hastaların seksüaliteye bakıș açıları ve yașadıkları sorunlar
}

\section{Sexual aspects of female patients with gynecological and breast cancer in different cultures and their problems}

Dilek Aygin®, Aysel Gülø

\section{öz}

Kanser, tüm dünyada ve ülkemizde giderek artan, biyolojik, psikolojik ve sosyal açıdan çok yönlü olarak bireyi etkileyen ve yaşam kalitesini bozan bir halk sağlığı sorunudur. Dolayısıyla yaşam kalitesinin önemli bir göstergesi olan cinsellik de olumsuz yönde etkilenmektedir. Sosyal çevreye, dine, kültüre, kişisel deneyimlere bağlı olan subjektif ve kompleks bir fenomen olan cinsellik kültürden ayrı düşünülemez. Toplum içinde kadının ne kadar önemli rollerinin olduğu bilinmektedir. Kanser olan kadın sadece kanser ve tedavilerine bağlı olarak olumsuz yönde etkilenmemekte, sosyo-kültürel açıdan da zorluklar yaşamaktadır. Buradan yola çıkarak, bu derleme makalede, farklı kültürlerin kansere yönelik algı, bilgi, tutum ve davranışları ile tanı, tedavi sürecinde yaklaşımlarının nasıl olduğu ve bireylerin psiko-sosyal durumları üzerinde ne gibi değişikliklere yol açtı̆̆ literatür ışığında incelendi.

Anahtar Kelimeler: bakış açısı, cinsellik, kadın, kanser, kültür

\section{ABSTRACT}

Cancer is a public health problem that affects the individual as versatile in terms of biologically, psychologically and socially, and break downs the quality of life, increasingly on the world and in our country. Therefore, sexuality, which is an important indicator of quality of life, is also affected negatively. Sexuality, a subjective and complex phenomenon that depends on social environment, religious, cultural, personal experiences, can not be considered apart from culture. It is known how important roles women have in society. Women with cancer are not only affected by the negative aspects due to cancer and their treatment, but also have difficulties in socio-cultural terms. Starting from this point, this review article examines the perception, knowledge, attitudes and behaviors of different cultures related to cancer, their diagnosis, their approaches to the treatment process and the changes in the psychosocial status of individuals.

Keywords: perspective, sexuality, woman, cancer, culture

\section{GíRiș}

İnsan sosyolojik, psikolojik, kültürel ve fizyolojik yönleriyle, birçok alt sistem ve yapıdan oluşan bütünleşik ve kompleks bir varlık olup değişen ve gelişen zaman içerisinde çevresel etkileşim dinamizmi altında, her geçen gün farklılaşmakta ve sahip olduğu bu biyo-psiko-sosyal yapısının devamlılığını sağlamaktadır. ${ }^{[1]}$ Bu yaşam döngüsü içerisinde bireyin sosyokültürel olarak sağlık kavramına bakış açısı değişmekte ve kaliteli yaşam kavramı öne çıkmaktadır. Dolayısıyla kaliteli yaşamı olumsuz yönde etkileyen, beklenilen ömrü kısaltan kanser önemli bir halk sağlığı sorunu

Sakarya Üniversitesi Sağlık Bilimleri Fakültesi, Cerrahi Hastalıkları Hemşireliği Anabilim Dalı, Sakarya

\section{Yazışma Adresi / Correspondence:}

Doç. Dr. Dilek Aygin

Sakarya Üniversitesi Sağlık Bilimleri Fakültesi, Esentepe Kampüsü 54050 Sakarya,

Türkiye

Tel. $\quad$ +902642956611

E-mail: daygin@sakarya.edu.tr

olarak görülmektedir. ${ }^{[2,3]}$ Küresel kanser yükü yaşam tarzı değişiklikleriyle birlikte dünya nüfusunun yaşlanması ve büyümesiyle her geçen gün artmaya devam etmektedir. ${ }^{[4]}$ Amerika Birleşik Devletleri'nde (ABD) her dört kişiden birinin ölümünden sorumlu tutulan kanserin, yakın gelecekte kalp hastalığından daha da fazla görüleceği ${ }^{[2]}$ ve 2018 yılı içerisinde 1,7 milyon kişinin kanser tanısı alacağı öngörülmektedir. ${ }^{[5]}$ Dünya çapındaki altı ölümden yaklaşık birinin kansere bağlı olduğu ve bu ölümlerin \%70'inin ise düşük ve orta gelirli ülkelerde meydana geldiği görülmektedir. ${ }^{[6]}$ ABD'de 2005-2014 yılları arasındaki kanser insidanslarına göre, kadınlarda yeni kanser olgularının sayısında anlamlı bir değişiklik olmadığı, erkeklerde ise kanser insidanslarının yaklaşık olarak yıllık \%2 gerilediği görülmüştür. 20062015 yılları arasındaki kanserden ölüm hızlarında ise hem kadınlarda hem de erkeklerde \% 1,5'luk bir düşüş yaşandığı bildirilmiştir. ${ }^{[7]}$

Avrupåda da mortalite ve morbiditenin en önemli ikincil nedeni olarak kanser karşımıza çıkmakta ve her yıl yaklaşık 3,7 milyon yeni vakaya kanser tanısı konulmaktadır. ${ }^{\left[{ }^{[]}\right.}$ 
Asya'da 2008 yılında 6,1 milyon kanser vakası varken, bu sayısının 2030 yılında 10,7 milyona yükseleceği; kanser nedenli ölümlerde ise 2008 yılında 4,1 milyon olan rakamın 2030'da 7,5 milyona ulaşacağı tahmin edilmektedir. ${ }^{[9]}$

Tüm dünyada olduğu gibi Türkiye'de de kanser nedeniyle morbidite ve mortalite oranlarının yüksek olduğ ${ }^{[10-12]}$ Türkiye İstatistik Kurumu 2016 yılı sonuçlarına göre her yıl yaklaşık olarak 174,000 kişiye yeni kanser tanısı konduğu bunların 80,577'sinin ise hayatını kaybettiği görülmektedir. ${ }^{[12,13]}$

Yüksek mortalite oranlarına sahip olmasıyla birlikte oldukça yaygın kronik bir hastalık olan kanser nedenli ölümler, erken tanı olanakları, gelişen radyoterapi, sistemik terapiler ve cerrahi teknikleri sayesinde azalmaktadır. ${ }^{[14,15]}$ Ancak tanı, tedavi süreci ve sonrasında bireyin sağlığı fizyolojik, psiko-sosyal ve kültürel olarak olumsuz yönde etkilenmekte ve yaşam kalitesi bozulmaktadır. ${ }^{[3,16,17]}$ Yaşam kalitesi ve genel sağlığın temel bileşenlerinden, kişilerin fiziksel ve ruhsal gereksinimlerinden biri olan cinsellik de bu süreçteki fonksiyonel olmayan değişikliklerden payını almakta ve kötü etkilenmektedir. Sonuçta \%40 ile \%100 arasında değişen oranlarda cinsel işlev bozuklukları meydana gelmektedir. ${ }^{[18,19]}$ Tanı ve tedavi sürecinde kadınlarda vajinal kuruluğun artması, disparoni, cinsel istek, arzu ve uyarılmanın azalması, zorlu orgazm gibi semptomlar görülebilmektedir. ${ }^{[20-23]}$

Seksüel sağlık, sadece hastalığın, işlev bozukluğunun ya da zayıflı̆̆ın bulunmaması değil; cinselliğe ilişkin fiziksel, emosyonel, zihinsel ve sosyal yönden tam bir iyilik hali olduğundan; olumlu ve saygılı bir yaklaşımı; ayrımcılık, şiddet ve zorlamadan arındırılmış, zevkli ve güvenli bir cinsel ilişkiyi de beraberinde getirmektedir. ${ }^{[24]}$ Herhangi bir sağlık problemi olmayan bireyler arasında dahi cinsel işlev bozukluklarının kadınların \%43'ünü, erkeklerin ise \%31 kadar büyük bir kısmını etkilediğ ${ }^{[25]}$ kanserli kadınlarda da cinsel disfonksiyon insidansının \%30 ile \%100 arasında değiştiğ ${ }^{[26-29]}$ düşünüldüğünde seksüalite; bireysel özelliklere, hastalık ya da farklı nedenlere, sosyokültürel değişimlere bağlı olarak birçok açıdan etkilendiği için bireyin bu konuda beklentilerini karşılayacak düzeyde dengeyi sağlayabilmesi ve sürdürebilmesi oldukça zordur. ${ }^{[30]}$

Cinsellik, evrensel bir kavram olmasına rağmen, sosyal anlamda normlara, kültüre, dine ve kişisel tecrübelere dayanan subjektif ve son derece karmaşık bir fenomen olduğundan, cinsel etkileşimler ve cinselliğin ifadesinin kültürel bağlamdan ayrı düşünülmesi söz konusu değildir. Sosyal ve kültürel yapı; cinsellik, cinsiyet rolü beklentileri, cinsel davranışlar, cinsel normlar, bu yönde inanç ve tutumların geliştirilmesinde önemli bir rol oynamaktadır. Dolayısıyla cinsel deneyim, toplum ve kültürden etkilenebileceği için, sosyokültürel değişiklikler de bireylerin kişisel, kişilerarası ve sosyal bağlamda yaşadığı deneyimleri etkileyecektir. ${ }^{[31]}$ Cinsel davranış, cinsel organın fiziki olarak uyarılması ya da bu uyarının zihinsel temsilleriyle harekete geçirilmesiyle ortaya çıkan olumlu etkilenme hali olan cinsel ödüle götüren herhangi bir eylemdir ve cinsel ödülün eksikliği ya da yokluğu cinsel hayal kırıklığına yol açmaktadır. İnsan cinsel davranışlarının toplumsal değerler aracılığıyla biyolojik unsurlara göre daha çok belirlendiği gerçeğini ortaya koyan cinsel hayal kırıklığı hipotezinin, sosyal öğrenme olgusu etrafında şekillendiği anlaşılmaktadır ve cinselliğe sosyal bir perspektif eklenmesi gerekliliği ortaya çıkmaktadır. ${ }^{[32]}$ Dolayısıyla sosyokültürel faktörlerin cinsellik üzerindeki etkisi, yalnızca hastalık süreci ve sonrası dönemde ortaya çıkan semptom ve bulgularla ilişkili değildir. ${ }^{[33]}$

Kanada'da yaşayan Asyalı kadınlarda, cinsel özgürlük ve cinsel işlevler üzerinde kültürleşmenin rolünü araştıran bir çalışmada; Avrupalı-Kanadalı kadınların Asya kökenli kadınlara göre, cinsel bilgi ve tecrübelerinin, cinsel istek, uyarılma ve zevklerinin daha yüksek düzeyde olduğu; cinsel yöndeki tutumlarının ise daha liberal bir görüntü çizdiği sonuçlarına ulaşılmıştır. Cinsel aktivite kaynaklı beklenen kaygı düzeyleri, Asya kökenli kadınlarda anlamlı derecede yüksek bulunurken; gruplar arasında ilişki doyumu ve cinsel işlev sorunları noktasında ise anlamlı bir farklılık tespit edilmemiştir. ${ }^{[33]}$

Farklı kültürel geçmişten gelen meme kanseri tanısı alan Kanadalı ve Avustralyalı kadınlarla yapılan bir literatür taramasında, duygusal boyutuyla küçük çocuk sahibi kadınların daha fazla stres, duygusal travmaya uğradıkları, aile ilişkilerinde gerginlik olduğu ve kötüye gittiği, hastalık sürecine uyumun daha kötü olduğu görülmüştür. Birçok kadın çocuklarının geleceği, refahı ve hastalıkla ilgili onlara dürüst olma noktasında endişe yaşadıklarını ifade etmiştir. ${ }^{[34]}$

Yaşa bağlı meydana gelen fiziksel değişiklikler, mutlak düzeyde cinsel işlevselliğin bozulmasına neden olmadığı gibi, ilerleyen yaşla birlikte, cinsel aktivitenin sürdürülmesi, iyi fiziksel ve mental sağlık, cinselliğe karşı olumlu tutum ve sağlıklı bir cinsel partnerin varlığı seksüel hayatın olumlu yönde değişimini sağlayan önemli unsurlardır. ${ }^{[35]}$

Yapılan araştırmalar kadınların ve erkeklerin yetmişli/seksenli yaşlarda da cinsel olarak aktif kaldıklarını ortaya koymaktadır ve bu süreçte özellikle kadınların menopoz dahil olmak üzere organik, işlevsel ve sosyodemografik değişkenlerden etkilenen, oldukça hassas bir popülasyonu temsil ettiği belirtilmektedir. ${ }^{[35-37]}$ Sadece kanser ve tedavilere bağlı olumsuz etkilerden söz edilemez. Bu hassas popülasyonun cinselliği farklı sosyokültürel yapılar içerisindeki 
değişimlerden de çok yönlü olarak etkilenmektedir. ${ }^{[38-40]}$ Aile üyeleri, kanserli hastalar için sosyal ve duygusal desteğin ana kaynağıdır ve hastalıkla baş etmede en önemli yapıdır. ${ }^{[4]}$ Meme kanseri tanısı sonrası çiftlerin hastalık ve sonrasındaki süreçle nasıl baş edeceklerini, bunu etkileyen kültürel faktörleri analiz eden araştırmacılar, dört kültür faktörünü ortaya koymuşlardır. Bunlar; aile sınırları, toplumsal cinsiyet rolleri, kişisel kontrol ve karşılıklı bağımlılıktır. Amerikalı çiftler cinsel yaşam, sosyal hayat, iletişim ve yakınlık, çiftler arası bağımlılık gibi unsurları en stresli durumlar olarak bildirirken; Çinli çiftler tedaviye karar verme ve destek noktasında yoğun stres yaşadıklarını belirtmişlerdir. ${ }^{[41]}$

Sosyokültürel faktörlerin kanser kontrolüne olası katkısını belirlemek amacıyla yapılan bir çalışmada Asyalı Amerikalıların düşük tarama oranlarına sahip olduğu; kullanılabilirlik, erişilebilirlik, kabul edilebilirlik, hesap verebilirlik, kullanım için risk/fayda hesaplamaları, yeterli sigortanın olmaması, yapılan taramaların avantajları veya nereden hizmet alınacağına dair bilgi eksikliklerinin söz konusu olması gibi nedenlerin önemli bir engel teşkil ettiği, kültürel düzeyde sağlık kavramı, beden imgesi, kanserin anlamı ve hastalıktan kaynaklanan sorunlara ilişkin kavramlarda da değişkenliklerin baş gösterdiği görülmektedir. ${ }^{[42]}$ Yapılan bir diğer çalışmada da Çinli Amerikalı kadınların meme kanserine ne anlam yükledikleri incelenmiş ve kültürel farklılıkların kadınları erken teşhis ve tedavide önemli derecede kısıtlayan predispozan bir faktör olduğu tespit edilmiştir. ${ }^{[43]}$ Japon-Amerikalılar ile Anglo-Amerikalılar arasında kanserle başa çıkma ve tedavi sürecine uyumu karşılaştıran bir araştırmada ise, her iki grubun da hastalık deneyimiyle olumlu yönde başa çıkmasına rağmen; gösterdikleri refleksif cevapların birbirinden farklı olduğu anlaşılmıştır. Japon-Amerikalılar kanser tedavi sürecini dayanıklılık olgusuna temellendirmiş; bu süreci sessizce ya da aile veya arkadaş üyeleriyle minimal düzeyde tartışarak geçirmeyi seçmişlerdir. Buna karşıllı Anglo-Amerikalıların tavırlarında kendine güven, sosyal destek ihtiyacını dile getirme ve sözel güç sağlama stratejileri söz konusu olmuş ve sosyal destek ağlarının daha büyük olduğu görülmüsstür. [44] Bir başka çalışmada, Çin-Amerikan, Japon-Amerikan ve Avrupa-Amerikan kadınlarının tepkileri karşılaştırılmış olup, meme kanseri teşhisi sonrası Çinli Amerikalı kadınların Japon veya Avrupa-Amerikalı kadınlara göre daha ileri evrede hastaneye başvurdukları saptanmıştır. ${ }^{[42]}$

Kanserin erken tespit edilmesi klinik sonuçları ve sağ kalımı geliştirmesine rağmen; taramaların düzenli olarak yapılması noktasında birtakım engellerle karşılaşılmaktadır. ${ }^{[45]} \mathrm{Bu}$ engeller içerisinde yer alan sosyal ve kültürel faktörlerin, Arap İsrail kadınının meme kanserinin erken tespiti için gerekli olan taramalara katılması üzerindeki etkisini değerlendiren bir çalışmada, odak gruplar oluşturularak görüşmeler gerçekleştirilmiş ve başlıca konular belirlenmiştir. Bunlar; kadının anne ve eş rolü, hastalığın üstesinden gelebilme, dini açıdan anlamlandırılması, Arap toplumundaki gizlilik algısı ve bu gizliliğe bağlı yaşanan sorunlardır. Kadınlar mastektomiden korktuklarını, bu ameliyatın kadınlık imajını ortadan kaldırdığını, eşlerinin başka kişilerle ilişki yaşamayı kendilerine hak görerek bunu meşrulaştırdığını, meme kanseri tanısının eş ve anne olarak işlevsiz bir süreci temsil ettiğini ifade etmişlerdir. Ayrıca kadınların toplumda önemsenmesi için güçlü olması gerektiğini, hastalık durumunun bir zayıflığı, çöküşü temsil ettiğini, böylesi bir tanı konulmasındansa intihar etmenin daha tercih edilebilecek bir yol olduğunu belirtmişlerdir. Dolayısıyla kadınların olası bir hastalık ihtimalinden kaçmak için mamografiyi erteledikleri, acı ve ağrı hissetmedikleri sürece tetkik yaptırmayı reddettikleri de ifade edilmiştir. Arap toplumunda kadınların kendilerini öteleme tutumlarının hastalık sürecine erteleme davranışı olarak yansıdığı ve bu süreçte toplum tarafından dışlanma korkusu (stigmaya maruz kalma) yaşadıkları belirlenmiştir. Dini boyutta bakıldığında birbirine zıt iki algının toplumda var olduğu; bir grubun bunu kabullenilmesi gereken bir kader olarak; diğer grubun ise her türlü çaba ve uğraş verilmesini, tanı, tetkik ve tedavi süreçlerine koşulsuz uyulmasını gerektiren bir durum olarak algıladıkları görülmüsstür. ${ }^{[46]}$

Kanser tanısıyla birlikte ortaya çıkan pek çok semptom ve belirti ile başa çıkmada bireysel niteliklerin yanı sıra sosyokültürel özelliklerin de etkili olduğu bir gerçektir. İranlı meme kanseri tanısı almış olan 82 kadınla yapılan bir çalışmada, kadınların kanser tanısı aldıktan sonra yaklaşık üçte birinde vajinal lubrikasyon ve fizyolojik heyecanda azalma, $\% 72$ 'sinde orgazm düzeyinde gerileme olduğu, cinsel doyumun orgazmdan bağımsız olarak daha genç ve evli kadınlarda yüksek olduğu görülmüştür. Hastalık öncesiyle karşılaştırıldığında yaş, medeni durum, eğitim ve istihdam düzeyi, beden algısı ve kocanın algılanan tutumu gibi faktörlerin cinsel tatminle yakından ilişkili olduğu sonucuna ulaşılmıştır. ${ }^{[47]}$

Kadınları servikal kansere karşı savunmasız bırakan sosyoekonomik ve kültürel faktörleri, tanı ve tedavi süreçlerinde karşılaştıkları güçlükleri değerlendirmeyi amaçlayan bir çalışmada, Etiyopyalı kadınları kanser tanısına karşı savunmasız bırakan unsurlar olarak; yoksulluk, erken yaşta evlilik, fazla sayıda doğum ve çokeşlilik gibi sosyokültürel uygulamaların olması gösterilmiştir. Tanı ve tedavi süreçlerinde geç kalınması, hastalığın tekrarlama korkusu, tedaviye bağlı dışkı ve idrar kaçırma gibi yan etkilerin gelişmesi 
ve bunun sosyal sonuçları da majör engeller olarak kadınlar tarafından ifade edilmiştir. Ayrıca tedavi ve konaklama ile ilgili yatak maliyetleri de ana ekonomik zorluklar olarak belirlenmiş ve temelde toplum algısının tıbbi tedaviye başlamadan önce geleneksel yöntemleri deneme yönünde olduğu saptanmıştır. ${ }^{[48]}$ Serviks kanseri tanılı Çinli-Avustralyalı kadınların kansere yönelik bilgi ve inançları incelendiğinde; bu kadınların sigara, alkol ve kontraseptif kullanımının kanser gelişiminde rol oynadığını ifade etmelerine karşın, kanser nedenleri, Pap smear testi, ne için yapıldığı ve gerekliliği hakkında bilgi eksikliklerinin olduğu, genel olarak kaderci bir tavır sergiledikleri, böyle bir durumda yapılacak hiçbir şeyin olmadığı gibi yaygın bir kanıya sahip oldukları tespit edilmiştir. Herhangi bir bulgu olmaksızın Pap smear testinin lüzumsuz olduğunu, servikal kanserin gelişigüzel birliktelikler yaşama sonucunda geliştiği inancının yaygın olduğu anlaşılmıştır. Doktor tavsiyesinin, taramayı yürüten doktorun kadın olmasının, doktorla ortak dil kullanımının kişileri tarama yaptırmaya iten kolaylaştırıcı faktörler olduğu; utanç, ağrı yaşama ve ulaşım problemlerinin ise engeller arasında görüldüğü saptanmıştır. ${ }^{[49]}$

Kadınlar kanser cerrahisinden sonra hastalığı ve tedavileriyle ilgili olarak birçok ciddi cinsel sorunla karşılaşmaktadır. ${ }^{[50,51]}$ Meme kanseri cerrahisi sonrası Koreli kadınlarda görülen cinsel işlev değişiklikleri ve hangi faktör/faktörlerin etkili olduğunun belirlenmesi amacıyla yürütülen çalışmada, cinsel açıdan aktif kadınların tedavi öncesi seviyelere kıyasla, cerrahi sonrası 3., 6. ve 12. aylarda cinsel ilgi ve cinsel aktivitede hafif veya ciddi sorun yaşadıklarıyla ilgili bildirimde bulunan kadın sayısının giderek arttığı belirlenmiştir. Erken dönem ortaya çikan cinsel sorunlar kemoterapi ile ilişkili bulunmuş, cerrahi prosedürün ise cinsel sorunlar üzerinde anlamlı bir etkiye sahip olmadığı görülmüştür. Post-menopozal kadınlarda ise, cerrahiden üç ay sonra; cinsel ilgide (hafif-şiddetli) yüksek oranda azalma olduğu, yorgunluk yaşandığı ve cinsel döngünün tüm alanlarında sorunların ortaya çıktığı belirlenmiştir. Ayrıca cerrahiden altı ay sonra özellikle kötü beden imajına sahip olanlarda; cinsel ilgide azalma, cinsel aktivitede ve tatminde sorunlar yaşandığı belirtilmişstir. ${ }^{[52]}$

Jinekolojik kanser sonrasında cinsel işlev bozuklukları ortaya çıkmakta, tedaviden yıllar sonra bile sağ kalanların çoğunu olumsuz olarak etkilemektedir. ${ }^{\left[{ }^{[3]}\right.} \mathrm{Bu}$ nedenle kişilerin cinsel işlev bozukluklarının erken evrede belirlenmesi ve müdahalelerinin yapılması önemlidir. Çinli kadınlar arasında jinekolojik kanser sonrasında yaşanan cinsel işlev bozukluğunun önemli bir endişe kaynağı olduğu ve bu kadınlarda \%70,5 gibi yüksek bir oranda cinsel disfonksiyon görüldüğü belirtilmiştir. Cinsel sorunların yüksek oranda olması ise tedavi edilme potansiyelinin zayıf olması, tekrarlayacağı korkusu, cinsel ilgi eksikliği, ağrı, cinsel aktivite sıklığında azalma ve yorgunluk gibi durumlarla ilişkilendirilmiştir. ${ }^{[54]}$ Başka bir araştırmada Norveçli jinekolojik kanser tedavisi gören kadınların cinsel açıdan aktif olanların \%54'ünün cinsel açıdan tatmin olmadığı, yaklaşık yarısının vajinal kuruluk yaşadığı ve \%41'inin penetrasyon sırasında ağrı ve rahatsızlık duyduğu belirlenmiştir. ${ }^{[55]}$

Birçok kanser hastası tedaviler ve sonrasındaki sürece adapte olsa da psiko-sosyal ve kültürel anlamda güçlük çekmektedir. ${ }^{[56]}$ Güney Asya kadınlarında damgalanma, kadın sağlığı kolektivizmi ve din/maneviyat gibi birkaç tema belirgin olarak öne çıkmıştır. Bu kadınlarda kanser bir tabu olarak görüldüğünden tartışılmamakta, ölümle ilişkili olduğu için korku yaratmakta ve kanserin bulaşıcı olduğu düşünülmektedir. Güney Asya kadınları kanserli kişilerin eşyalarını paylaşarak ya da meme kanseri olan bir kadınla temas kurularak kanserin yayılabileceğine inandıkları için, bu durum korku ve sosyal izolasyonla sonuçlanmıştır. Dolayısıyla damgalanma korkusu evlilik umutlarını azalttığı için tanının gizlenmesine, aktif bir şekilde tedavi arayışından vazgeçilmesine yol açmıştır. Aynı zamanda kadına yönelik cinsiyet ve cinsel rol beklentileri semptomlara yönelik farkındalıklarını geciktirmiş olup; bireylerde bir stresör haline gelmiştir. ${ }^{[57]}$

Stoacılık ve iffet Asya kültürlerinde belirgin değerler olarak yer almaktadır ve bu kültürde memeler özel, gizli tutulması gereken organlar olarak görüldüğü için açıkça konuşulamamaktadır. Dokunma ile ilişkili olumsuz çağrışımlar nedeniyle tıbbi yardım almalarının da engellendiği belirlenmiştir. Kadınların farkındalık düzeylerinin düşük olması da tanıyı geciktiren unsurlardan biri olmuştur. Psiko-sosyal açıdan kadınların olumsuz tutum ve davranışlarla karşılaştığı, bazılarının evdeki tüm sorumluluklarının aynı şekilde devam ettiği, bazılarının da aile üyelerinin bu hastalığı kadının kişisel bir hatası olarak gördükleri için anlayış gösterilmediğinden yakındığı bildirilmiştir. Dinsel boyutuyla bakıldığında kaderci bir yaklaşımla birlikte, bazıları tanısının ilahi bir mesaj olduğunu, diyet, egzersiz ve iyileştirme gibi yaşam tarzı değişiklikleri yapmaları için teşvik ettiğine inanmaktadır. ${ }^{[57]}$

Ummanlı meme kanserli kadınlarla yürütülen bir çalışmada, stres, belirsizlik, aile üyelerinin tepkileri, toplumun meme kanserli kadına bakış açısı, yeniden nüks etme olasılığı gibi nedenlerle kendilerini tehdit altında hissettikleri ve endişelendikleri görülmüştür. Meme kanseri tanısı almanın ölüm cezasıyla eş değer olarak algılandığı, hastalığın toplumda insanların duygularını incitecek bir durum olduğu inancının da sosyal izolasyona neden olduğu belirtilmiştir. Kadınların çoğunluğunun da meme kanserinin 
kalıtsal bir hastalık olduğuna inandığı ve bu hastalığı genetik miras olarak kızlarına bırakma endişesi yaşadıkları ifade edilmiştir. ${ }^{[58]}$

Tarih boyunca kadınların algılanışı, annelik, bakım, beslenme, hassasiyet ile ilişkilendirildiğinden; kadınlar ev işleri, çocuk yetiştirme ve doğum gibi konulardan sorumlu olmuştur. Modernleşmeyle birlikte kadının toplumdaki rolü aktifleşmesine rağmen, kadınların aile içindeki rolü aynı kalmış, bölgelere göre sağlık ve refah düzeyleri değişkenlik göstermiştir. Özellikle meme kanseri bu açıdan önemli bir sorun olarak algılanmıştır. ${ }^{[59]}$ Kanser tedavisi gören Türk kadınlarla gerçekleştirilen tanımlayıcı ve kesitsel tipteki araştırmada, sağlıklı oldukları zamanlarda cinsel sorun yaşama oranları \%16,1 iken haftada 3 veya daha fazla seks yaptıklarını belirten kadınların, tedavi sonrasinda \%94,6'ya varan oranlarda cinsel sorun yaşamaya başladıkları belirtilmiştir. ${ }^{[00]}$ Aygin ve Aslan'ın meme kanserli Türk kadınlarla yürüttükleri çalışmada benzer sonuçlar elde edilmiş olup, kanser tanısı öncesi sağlıklı cinsel yaşama sahip olduğunu belirten kadınların cerrahi sonrasinda kemoterapi ve radyoterapinin de etkisiyle yarısından fazlasında cinsel işlev bozukluklarının ortaya çıktığı belirlenmiştir. ${ }^{\left[{ }^{[1]}\right]}$ Türk kadınlarında kanserin psikolojik ve psiko-sosyal etkileri araştırıldığında kanser hastalarının sıklıkla yalnızlaştıkları ve işe geri dönme durumlarında birtakım istenmedik durumlarla karşılaştıkları saptanmıştır. Marjinalleşme hatta damgalanmanın \%30 ila \%40 gibi değişen oranlarda baş gösterdiği; kayg1, adaptasyon bozukluğu ve depresyon gibi durumların en yaygın görülen psikolojik rahatsılılklar olduğu belirlenmiştir. ${ }^{[59]}$ Kanserin psikolojik ve psikososyal yönünün araştırıldığı bir diğer çalışmada, Türkiye'de hastanın beklentisi ve tedaviye olan işbirliğine ilişkin psikolojik, kültürel, sosyal ve çevresel etkilerin önemi vurgulanmış, hastalığa ilişkin bilgi sahibi olmanın olumlu problem çözme stratejileri ile içi içe olduğu belirtilmiştir. Hastalı̆̆ğı algılanmasında özellikle kültürel inançlar, kişisel deneyimler, sosyal iletişim gibi yapıların belirleyici olduğu anlaşılmıştır. ${ }^{[62]}$ Türkiye'de düşük-orta sosyoekonomik düzeye sahip kanser hastalarının hastalık algısı üzerine yapılan araştırmada, hastalığa ilişkin bilgi eksikliğinin kişileri fatalistik bir algıya sürüklediği saptanmıştır. Hastalar kanser olma nedenlerini inanç boyutuyla açıkladıklarında, kendilerinin cezalandırıldığını düşündüklerini ve suçluluk duygusu hissettiklerini dile getirmişlerdir. ${ }^{[59]}$

\section{SONUÇ}

Sonuç olarak kanser, gerek hastalığın kendisi gerekse uygulanan tedaviler nedeniyle, birtakım fizyolojik değişimlere yol açmasının yanı sıra, bireylerin ve aile üyelerinin yaşam kalitesinin azalmasıyla ilişkili olarak depresyon, kaygı, benlik saygısının bozulması, stres, psikolojik ve duygusal refahta azalma gibi ciddi ve şiddetli psikososyal etkilere neden olmaktadır. ${ }^{[63-68]}$ Bireyin fiziksel sağlık, psikolojik durum, bağımsızlık seviyesi, kişisel inançları, sosyal ilişkileri gibi varlığının tüm yönlerini kapsayan yaşam kalitesinin önemli bir boyutu olan cinsellik de bu süreçte çok boyutlu olarak etkilenmektedir. ${ }^{[66,69,70]}$

\section{Hakem Değerlendirmesi \\ Dış bağımsız \\ Çıkar Çatışması \\ Yazarlar çıkar ilişkisi olmadığını beyan etmişlerdir. \\ Finansal Destek \\ Herhangi bir mali destek alınmamıştır.}

\section{Peer-review}

Externally peer-reviewed.

Conflict of Interest

No conflict of interest was declared by the authors.

Financial Disclosure

No financial disclosure was received.

\section{KAYNAKLAR}

1. Maden HA. Yönetim ve Kültür. DTCF Dergisi 2018. http:// www.dtcfdergisi.ankara.edu.tr/index.php/dtcf/article/ download/4813/4720 [Erişim Tarihi: 10.02.18].

2. Kemp BR, Ferraro KF, Morton PM, Mustillo SA. Early Origins of Adult Cancer Risk Among Men and Women: Influence of Childhood Misfortune? J Aging Health 2018;30:140-63. [CrossRef]

3. Gao H, Xiao M, Bai H, Zhang Z. Sexual Function and Quality of Life Among Patients With Endometrial Cancer After Surgery. Int J Gynecol Cancer 2017;27:608-12. [CrossRef]

4. Johansen S, Cvancarova M, Ruland C. The Effect of Cancer Patients' and Their Family Caregivers' Physical and Emotional Symptoms on Caregiver Burden. Cancer Nurs 2018;41:91-9. [CrossRef]

5. American Cancer Society database: Cancer Facts \& Figures 2018 fact sheet retrieved. https://www.cancer.org/research/cancer-factsstatistics/all-cancer-facts-figures/cancer-facts-figures-2018.html [Erişim Tarihi: February 11, 2018].

6. World Health Organization database: Cancer fact sheet retrieved. http://www.who.int/mediacentre/factsheets/fs297/en/ [Erişim Tarihi: February 10, 2018].

7. Siegel RL, Miller KD, Jemal A. Cancer Statistics, 2018. Ca Cancer J Clin 2018;68:7-30. [CrossRef]

8. World Health Organization Regional Office for Europe database: from data and statistics fact sheet retrieved. www.euro.who.int/en/ [Erişim Tarihi: February 11, 2018].

9. Sankaranarayanan R, Ramadas K, Qiao YL. Managing the changing burden of cancer in Asia. BMC Med 2014;12:1-17. [CrossRef]

10. National Cancer Institute database: What is Cancer? https://www. cancer.gov/about-cancer/understanding/what-is-cancer [Erişim Tarihi: February 12, 2018].

11. Cancer Research UK database: What is cancer?. www. cancerresearchuk.org/about-cancer/what-is-cancer [Erişim Tarihi: February 12, 2018]. 
12. Türkiye Kanser İstatistikleri. http://kanser.gov.tr/Dosya/ca istatistik/ANA_rapor_2013v01_2.pdf [Erişim Tarihi: 12.02.2018].

13. Türkiye İstatistik Kurumu. Ölüm Nedeni İstatistikleri, 2016. http://www.tuik.gov.tr/PreHaberBultenleri.do?id=24572 [Erişim Tarihi: 12.02.2018].

14. Albabtain H, Alwhaibi M, Alburaikan K, Asiri Y. Quality of life and complementary and alternative medicine use among women with breast cancer. Saudi Pharm J 2018;26:416-21. [CrossRef]

15. Fridriksdottir N, Gunnarsdottir S, Zoëga S, Ingadottir B, Hafsteinsdottir EJG. Effects of web-based interventions on cancer patients' symptoms: review of randomized trials. Support Care Cancer 2018;26:337-51. [CrossRef]

16. Mishra SI, Rishel Brakey H, Kano M, Nedjat-Haiem FR, Sussman AL. Health related quality of life during cancer treatment: Perspectives of young adult (23-39 years) cancer survivors and primary informal caregivers. Eur J Oncol Nurs 2018;32:48-54. [CrossRef]

17. Warapornmongkholkul A, Howteerakul N, Suwannapong N, Soparattanapaisarn N. Self-efficacy, social support, and quality of life among primary family-member caregivers of patients with cancer in Thailand. J Health Res 2018;32:111-22. [CrossRef]

18. Bober SL, Varela VS. Sexuality in Adult Cancer Survivors: Challenges and Intervention. J Clin Oncol 2012;30:3712-9. [CrossRef]

19. Jung D, Kim JH. Effects of a sexual health care nursing record on the attitudes and practice of oncology nurses. Sex Reprod Healthc 2016;9:21-6. [CrossRef]

20. Male DA, Fergus KD, Cullen K. Sexual identity after breast cancer: sexuality, body image, and relationship repercussions. Curr Opin Support Palliat Care 2016;10:66-74. [CrossRef]

21. Pinar G, Kaplan S, Akalın A, Abay H, Ayhan A, Ayhan Y. Evaluation of sexual dysfunction and affecting factors in Turkish women with gynecological cancer. Sex Disabil 2016;34:49-62.

22. Incrocci L. Radiotherapy for prostate cancer and sexual health. Transl Androl Urol 2015;4:124-30. [CrossRef]

23. Seidler ZE, Lawsin CR, Hoyt MA, Dobinson KA. Let's talk about sex after cancer: exploring barriers and facilitators to sexual communication in male cancer survivors. Psychooncology 2016;25:670-676. [CrossRef]

24. World Health Organization database: Defining sexual health. http://www.who.int/reproductivehealth/topics/sexual_health/sh_ definitions/en/ [visited February 17,2018].

25. Rosen RC. Prevalence and risk factors of sexual dysfunction in men and women. Curr Psychiatry Rep 2000;2:189-95. [CrossRef]

26. Sanchez Varela V, Zhou EZ, Bober SL. Management of sexual problems in cancer patients and survivors. Curr Probl Cancer 2013;37:319-52. [CrossRef]

27. Hautamäki-Lamminen K, Lipiäinen L, Beaver K, Lehto J, Kellokumpu-Lehtinen PL. Identifying cancer patients with greater need for information about sexual issues. Eur J Oncol Nurs 2013;17:9-15. [CrossRef]

28. Dizon DS, Suzina D, McIlvennaa S. Sexual Health as a Survivorship Issue for Female Cancer Survivors. Oncologist 2014;19:202-10. [CrossRef]

29. Dizon DS, Katz A. Overview of sexual dysfunction in male cancer survivors. 2018. https://www.uptodate.com/contents/overviewof-sexual-dysfunction-in-male-cancer-survivors [Erişim Tarihi: February 17,2018].

30. Dinçer Y, Oskay Ü. Kanser ve cinsellik. Androloji Bülteni 2015;17:311-4. https://www.journalagent.com/androloji/pdfs/ AND_17_63_311_314.pdf
31. Khalaf ZF, Liow JW, Low WY, Ghorbani B, Merghati-Khoe E. Young Women's Experience of Sexuality: A Battle of Pleasure and Sexual Purity in the Context of Malaysian Society. Sexuality \& Culture 2018.

32. Stuger J. An Essay on Sexual Frustration as the Cause of Breast Cancer in Women: How Correlations and Cultural Blind Spots Conceal Causal Effects. Breast J 2012;18:168-71. [CrossRef]

33. Brotto LA, Chik HM, Ryder AG, Gorzalka BB, Seal BN. Acculturation and Sexual Function in Asian Women. Arch Sex Behav 2005;34:613-26. [CrossRef]

34. Reidy M, Denieffe $S$. Breast cancer in younger women from diverse cultural backgrounds. Br J Nurs 2014;24:S19-26. [CrossRef]

35. DeLamater J, Koepsel ER, Johnson T. Changes, changes? Women's experience of sexuality in later life. Sex Relat Ther 2017:1-17. [CrossRef]

36. Sánchez SC, Chedraui P, Pérez-López FR, Ortiz-Benegas ME, Palacios-De Franco Y Evaluation of sexuality in a Paraguayan midaged female urban population using the six-item Female Sexual Function Index. Climacteric 2016;19:256-60. [CrossRef]

37. Krychman ML. Declining sexuality at midlife. Menopause 2017;24:358-9. [CrossRef]

38. Shaw LK, Sherman KA, Fitness J, Elder E; Breast Cancer Network Australia. Factors associated with romantic relationship formation difficulties in women with breast cancer. Psychooncology 2018;27:1270-6. [CrossRef]

39. Rosenkrantz DE, Mark KP. The Sociocultural Context of Sexually Diverse Women's Sexual Desire. Sexuality \& Culture 2018;22:22042. [CrossRef]

40. Benedict C, Philip EJ, Baser RE, Carter J, Schuler TA, Jandorf L, et al. Body image and sexual function in women after treatment for anal and rectal cancer. Psychooncology 2016;25:316-22. [CrossRef]

41. Kayser K, Cheung PKH, Rao N, Chan YCL, Chan Y, Lo PHY. The Influence of Culture on Couples Coping with Breast Cancer: A Comparative Analysis of Couples from China, India, and the United States. J Psychosocial Oncol 2014;32:264-88. [CrossRef]

42. Kagawa-Singer M. A Socio-cultural Perspective on Cancer Control Issues for Asian Americans. Asian Am Pac Isl J Health 2000;8:12-7.

43. Mo B. Modesty, sexuality, and breast health in Chinese-American women. West J Med 1992;157:260-4.

44. Wellisch D, Kagawa-Singer M, Reid SL, Lin YJ, Nishikawa-Lee S, Wellisch M. An exploratory study of social support: a cross-cultural comparison of Chinese-, Japanese-, and Anglo-American breast cancer patients. Psychooncology 1999;8:207-19. [CrossRef]

45. McWilliams L, Bellhouse S, Yorke J, Cowan R, Heaven C, French DP. The acceptability and feasibility of lay-health led interventions for the prevention and early detection of cancer. Psychooncology 2018. [CrossRef]

46. Baron-Epel O, Granot M, Badarna S, Avrami S. Perceptions of Breast Cancer Among Arab Israeli Women. Women Health 2004;40:100-16. [CrossRef]

47. Garrusi B, Faezee H. How do Iranian Women with Breast Cancer Conceptualize Sex and Body Image? Sex Disabil 2008;26:159-65. [CrossRef]

48. Tadesse SK. Socio-economic and cultural vulnerabilities to cervical cancer and challenges faced by patients attending care at Tikur Anbessa Hospital: a cross sectional and qualitative study. BMC Women's Health 2015;15:1-12. [CrossRef]

49. Kwok C, White K, Roydhouse JK. Chinese-Australian Women's Knowledge, Facilitators and Barriers Related to Cervical Cancer Screening: A Qualitative Study. J Immigr Minor Health 2011;13:1076-83. [CrossRef] 
50. Trivers KT, Patterson JR, Roland KB, Rodriguez JL. Issues of ovarian cancer survivors in the USA. a literature review. Support Care Cancer 2013;21:2889-98. [CrossRef]

51. Guntupalli SR, Sheeder J, Ioffe Y, Tergas A, Wright JD, Davidson SA, et al. Sexual and Marital Dysfunction in Women With Gynecologic Cancer. Int J Gynecol Cancer 2017;27:603-7. [CrossRef]

52. Yang EJ, Kim SW, Heo CY, Lim JY. Longitudinal changes in sexual problems related to cancer treatment in Korean breast cancer survivors: a prospective cohort study. Support Care Cancer 2011;19:909-18. [CrossRef]

53. Bober SL, Recklitis CJ, Michaud AL, Wright AA. Improvement in sexual function after ovarian cancer: Effects of sexual therapy and rehabilitation after treatment for ovarian cancer. Cancer 2018;124:176-82. [CrossRef]

54. Zeng YC, Li Q, Li X, Loke AY. Chinese women's sexuality concerns after gynecologic cancer. Cancer Nurs 2012;35:257-64. [CrossRef]

55. Sekse RJT, Hufthammer KO, Vika ME. Sexual activity and functioning in women treated for gynaecological cancers. J Clin Nurs 2016;26:400-10. [CrossRef]

56. Thieme M, Einenkel J, Zenger M, Hinz A. Optimism, pessimism and self-efficacy in female cancer patients. Jpn J Clin Oncol 2017;47:849-55. [CrossRef]

57. Bedi M, Devins MG. Cultural considerations for South Asian women with breast cancer. J Cancer Surviv 2016;10:31-50. [CrossRef]

58. Al-Azri M, Al-Awisi H, Al-Rasbi S, El-Shafie K, Al-Hinai M, AlHabsi H, Al-Moundhri M. Psychosocial Impact of Breast Cancer Diagnosis Among Omani Women. Oman Med J 2014;29:43744. [CrossRef]

59. Özkan S, Özkan M, Armay Z. Cultural Meaning of Cancer Suffering. J Pediatr Hematol 2011;33:S102-4. [CrossRef]

60. Demirtas B, Pinar G. Determination of sexual problems of Turkish patients receiving gynecologic cancer treatment: a cross-sectional study. Asian Pac J Cancer Prev 2014;15:6657-63. [CrossRef]
61. Aygin D, Eti Aslan F. Meme kanserli kadınlarda cinsel işlev bozukluklarının incelenmesi. Meme Sağlığı Derg 2008;4:105-14.

62. Kocaman N, Özkan M, Armay Z, Özkan S. Hastalık Algısı Ölçeğinin Türkçe uyarlamasının geçerlilik ve güvenilirlik çalışması. Anadolu Psikiyatri Derg 2007;8:271-80.

63. Lorusso D, Bria E, Costantini A, Di Maio M, Rosti G, Mancuso A. Patients' perception of chemotherapy side effects: Expectations, doctor-patient communication and impact on quality of life - An Italian survey. Eur J Cancer Care 2017;26:e12618. [CrossRef]

64. Arikawa AY, Kaufman BC, Raatz SK, Kurzer MS. Effects of a parallel-arm randomized controlled weight loss pilot study on biological and psychosocial parameters of overweight and obese breast cancer survivors. Pilot Feasibility Stud 2018;4:1-12. [CrossRef]

65. Ohnishi S, Takeda H. Herbal medicines for the treatment of cancer chemotherapy-induced side effects. Front Pharmacol 2015;6:14. [CrossRef]

66. Rojas KE, Matthews N, Raker C, Clark MA, Onstad M, Stuckey A, Gass J. Body mass index (BMI), postoperative appearance satisfaction, and sexual function in breast cancer survivorship. J Cancer Surviv 2018;12:127-33. [CrossRef]

67. Costa P, Cardoso JM, Louro H, Dias J, Costa L, Rodrigues R, et al. Impact on sexual function of surgical treatment in rectal cancer. Braz J Urol 2018;44:141-9. [CrossRef]

68. Chow KM, So WKW, Choi KC, Chan CWH. Sexual function, psychosocial adjustment to illness, and quality of life among Chinese gynaecological cancer survivors. Psychooncology 2018;27:1257-63. [CrossRef]

69. Cairo Notari S, Favez N, Notari L, Panes-Ruedin B, Antonini T, Delaloye JF. Women's experiences of sexual functioning in the early weeks of breast cancer treatment. Eur J Cancer Care 2018;27:e12607. [CrossRef]

70. Bajpai J, Shylasree TS. Sexual quality of life in breast and ovarian cancer survivors: Tip of the iceberg! J Cancer Policy 2018;15:1003. [CrossRef] 